\title{
Treatment choices and neuropsychological symptoms of a large cohort of early MS
}

Olga von Bismarck, medstudent, * Theresa Dankowski, PhD,* Björn Ambrosius, PhD, Nicole Hessler, Msc, Gisela Antony, Dipl-Psych, Andreas Ziegler, PhD, Muna-Miriam Hoshi, MD, Lilian Aly, MD, Felix Luessi, MD, Sergiu Groppa, MD, Luisa Klotz, MD, Sven G. Meuth, MD, Björn Tackenberg, MD, Muriel Stoppe, MD, Florian Then Bergh, MD, Hayrettin Tumani, MD, Tania Kümpfel, MD, Martin Stangel, MD, Christoph Heesen, MD, Brigitte Wildemann, MD, Friedemann Paul, MD, Antonios Bayas, MD, Clemens Warnke, MD, Frank Weber, MD, Ralf A. Linker, MD, Ulf Ziemann, MD, Uwe K. Zettl, MD, Frauke Zipp, MD, Heinz Wiendl, MD, Bernhard Hemmer, MD, Ralf Gold, MD, and Anke Salmen, MD On behalf of the German Competence Network Multiple Sclerosis (KKNMS)

Neurol Neuroimmunol Neuroinflamm 2018;5:e446. doi:10.1212/NXI.0000000000000446

\section{Abstract}

\section{Objective}

To assess clinical characteristics, distribution of disease-modifying treatments (DMTs), and neuropsychological symptoms in a large cohort of patients with early-stage MS.

\section{Methods}

The German National MS Cohort is a multicenter prospective longitudinal cohort study that has recruited DMT-naive patients with clinically isolated syndrome (CIS) and relapsingremitting MS (RRMS) since 2010. We evaluated their baseline characteristics and the prevalence of neuropsychological symptoms.

\section{Results}

Of 1,124 patients, with a 2.2:1 female-to-male ratio and median age at onset of 31.71 years (interquartile range [IQR]: 26.06-40.33), 44.6\% and 55.3\% had CIS and RRMS, respectively. The median Expanded Disability Status Scale (EDSS) score at baseline was 1.5 (IQR: 1.0-2.0). A proportion of $67.8 \%$ of patients started DMT after a median time of 167.0 days (IQR 90.0-377.5) since the first manifestation. A total of $64.7 \%$ and $70.4 \%$ of the 762 patients receiving early DMT were classified as CIS and RRMS, respectively. Fatigue, depressive symptoms, and cognitive dysfunction were detected in $36.5 \%, 33.5 \%$, and $14.7 \%$ of patients, respectively.

\section{Conclusion}

Baseline characteristics of this large cohort of patients with early, untreated MS corroborated with other cohorts. Most patients received early DMT within the first year after disease onset, irrespective of a CIS or RRMS diagnosis. Despite the low EDSS score, neuropsychological symptoms affected a relevant proportion of patients.
Correspondence

Dr. Salmen

anke.salmen@insel.ch
*These authors contributed equally to the manuscript.
From the Department of Neurology (O.v.B., B.A., R.G., A.S.), St. Josef-Hospital, Ruhr-University Bochum; Institute of Medical Biometry and Statistics (T.D., N.H., A.Z.), University of Lübeck,
University Hospital Schleswig-Holstein, Campus Lübeck; Central Information Office (ClO) (G.A.), Philipps-University Marburg, Germany; School of Mathematics (A.Z.), Statistics and Computer
Science, University of KwaZulu-Natal, Pietermaritzburg, South Africa; Department of Neurology (M.-M.H., L.A., B.H.), Klinikum rechts der Isar, Technical University of Munich; Munich Cluster for
Systems Neurology (SyNergy) (L.A., B.H.); Department of Neurology (F.L., S.G., F.Z.), University Medicine Mainz, Johannes Gutenberg University Mainz; Department of Neurology (L.K., S.G.M.,,
H.W.), University Hospital Münster; Department of Neurology (B.T.), Philipps-University Marburg; Department of Neurology (M.Stoppe, F.T.B.), University of Leipzig; Department of Neurology
(H.T.), University of Ulm; Clinic of Neurology Dietenbronn (H.T.), Schwendi; Institute of Clinical Neuroimmunology (T.K.), Ludwig Maximilian University of Munich; Department of Neurology
(M.Stangel), Hannover Medical School; Institut für Neuroimmunologie und Multiple Sklerose (C.H.), Universitätsklinikum Hamburg-Eppendorf; Department of Neurology (B.W.), University of
Heidelberg; NeuroCure Clinical Research Center and Experimental and Clinical Research Center (F.P.), Charité-University Medicine Berlin and Max Delbrueck Center for Molecular Medicine;
Department of Neurology (A.B.), Klinikum Augsburg; Department of Neurology (C.W.), Heinrich-Heine-University, Düsseldorf; Department of Neurology (C.W.), University Hospital Köln;
Neurology (F.W.), Max-Planck-Institute of Psychiatry, Munich; Neurological Clinic (F.W.), MATERNUS Kliniken AG, Bad Oeynhausen; Department of Neurology (R.A.L.), University Hospital
Erlangen; Department of Neurology \& Stroke (U.Z.), Hertie Institute for Clinical Brain Research, Eberhard-Karls-University Tübingen; Department of Neurology (U.K.Z.), University of Rostock,
Germany; and Department of Neurology (A.S.), Inselspital Bern, University Hospital and University of Bern, Switzerland.

Funding information and disclosures are provided at the end of the article. Full disclosure form information provided by the authors is available with the full text of this article at Neurology.org/NN. 


\section{Glossary}

BDI-II = Beck Depression Inventory II; BMI = body mass index; CI = confidence interval; $\mathbf{C I S}=$ clinically isolated syndrome; DMT = disease-modifying treatment; EDSS = Expanded Disability Status Scale; FSMC = Fatigue Scale for Motor and Cognitive Functions; IQR = interquartile range; MSFC = Multiple Sclerosis Functional Composite; MUSIC = Multiple Sclerosis Inventory of Cognition; RRMS = relapsing-remitting MS.

Health insurance data of 2010 revealed that 199,505 patients have MS in Germany, resulting in a prevalence of 289/ 100,000 inhabitants. ${ }^{1}$ More current epidemiological data from Germany, however, are scarce.

For a broad spectrum of disease-modifying treatments (DMTs), data of phase III trials on safety and efficacy with selected populations can only partly be transferred to realworld settings. ${ }^{2}$ Published studies may be outdated at the time of publication in a rapidly changing DMT landscape. In an observational study, the time from the onset of clinically isolated syndrome (CIS) to DMT varied from 15.2 months, for patients recruited during the 2002-2007 period, to 41.5 months, for those recruited during the 1995-2001 period. $^{3}$ Compared with more recent data $(61.6 \%),{ }^{4}$ the proportion of patients receiving DMT (38.3\%) was low.

The prevalence of comorbidity in MS varies considerably. ${ }^{5}$ Compared with the reported prevalence of fatigue in population-based samples $(6.1 \%-30.5 \%),{ }^{6,7}$ that in MS ranges from $31.3 \%$ to $81 \% .^{8-11}$ Similarly, the reported prevalence of depression in MS ranges from $6.9 \%$ to $70.1 \%^{12}$ and from $3.8 \%$ to $10.2 \%$ in the German population. ${ }^{13}$ Cognitive decline is reportedly prevalent in MS $(43 \%-70 \%){ }^{14}$ The estimated prevalence of mild cognitive impairment at the age of 60 years or above is $5.9 \%{ }^{15}$ Taken together, these findings indicate that premature aging of the brain alone cannot explain the high prevalence of cognitive impairment in MS. Data on associations of fatigue, depression, cognitive decline, and physical disability depict varying results. ${ }^{16,17}$ The discrepancies in both the prevalence and associations of these domains may have various causes: many cohorts are small, there is a variation in assessment tools, and MS populations were differently selected (or unselected). ${ }^{8-10,14}$

The aim of this study was to assess clinical characteristics of a large cohort of patients with CIS or early relapsing-remitting MS (RRMS), DMT behavior, and neuropsychological symptoms.

\section{Methods}

\section{Standard protocol approvals, registrations, and patient consents}

This multicenter prospective longitudinal observational cohort study (German National MS Cohort) was approved by the ethics committee of Ruhr-University Bochum (registration no. 3714-10), and consecutively, all local committees of the participating centers ( 22 centers in Germany). All patients provided written informed consent.

\section{Inclusion and exclusion criteria and recruitment}

Table 1 outlines the inclusion and exclusion criteria. A total of 1,212 patients were recruited and included between August 2010 and December 2014.

\section{Assessment plan}

Patient visits were scheduled annually until year 2 and subsequently every other year for 10 years. Table 2 outlines the

Table 1 Inclusion and exclusion criteria of the German National MS Cohort

\begin{tabular}{|c|c|}
\hline Inclusion criteria & Exclusion criteria \\
\hline 1) Age $\geq 18 \mathrm{yrs}$; male and female & $\begin{array}{l}\text { 1) Previous use of DMT (irrespective of administered short- } \\
\text { term relapse treatment) }\end{array}$ \\
\hline 2a) Diagnosis of CIS within 6 mo before inclusion-fulfilling 3 of 4 Barkhof criteria ${ }^{33}$ & 2) PPMS and other progressive forms of MS \\
\hline $\begin{array}{l}\text { OR-fulfilling } 2 \text { of } 4 \text { Barkhof criteria }{ }^{33} \text { with supportive findings in CSF (intrathecal IgG } \\
\text { production/oligoclonal bands) or in VEP }\end{array}$ & 3) Concurrent progressive neurologic diseases \\
\hline OR-fulfilling RRMS diagnosis based on McDonald criteria $2010^{29}$ & $\begin{array}{l}\text { 4) Conditions interfering with the assessment plan (e.g., } \\
\text { general contraindication for MRI) }\end{array}$ \\
\hline
\end{tabular}

2b) Diagnosis of RRMS based on McDonald criteria $2005^{34}$ within 2 yrs before inclusion 
Table 2 Assessment plan of the German National MS Cohort

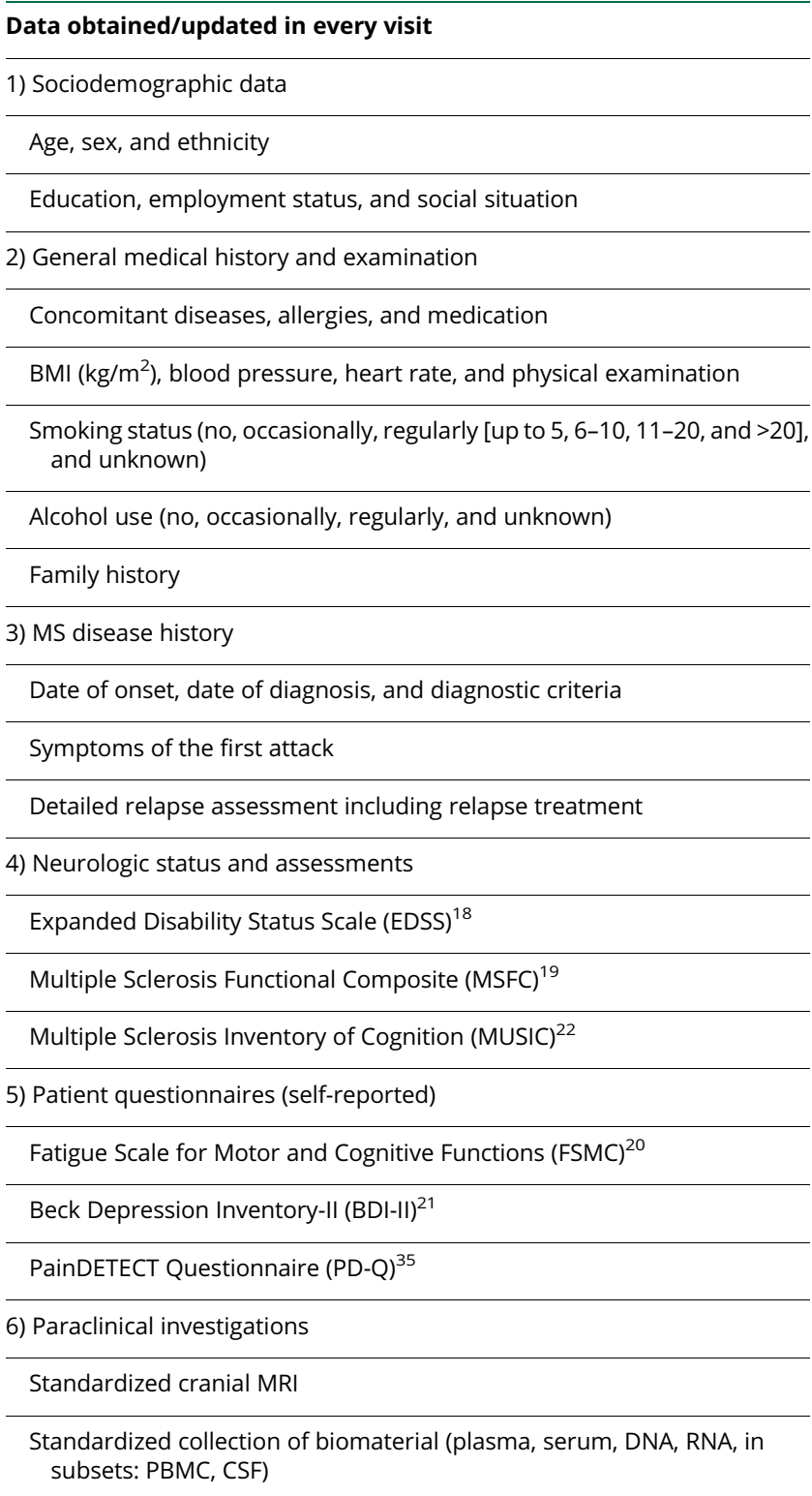

Abbreviations: $\mathrm{BMI}=$ body mass index; $\mathrm{PBMC}=$ peripheral blood mononuclear cell.

detailed assessment plan. The centers consented to all the included parameters before the initiation of the study. If available, well-established international scales, such as the Expanded Disability Status Scale (EDSS) ${ }^{18}$ or the Multiple Sclerosis Functional Composite (MSFC), ${ }^{19}$ were implemented. For neuropsychological measurements, scales that were already implemented in routine assessments in some or most of the centers were preferentially chosen. Minimal, mild, moderate, or severe degree of symptoms were defined according to the respective test manual.

\section{Statistical analysis}

Descriptive statistics summarized baseline measurements. We defined the medians and interquartile ranges (IQRs) of continuous variables and absolute and relative frequencies of categorical variables. Explorative correlation analyses (without multiple testing correction) were performed using Kendall's taub with $95 \%$ CIs, which were constructed using 2000 bootstrap samples to determine convergent and discriminant validity relationships. All analyses were performed using statistical software $\mathrm{R}$ version 3.3.0 ( $\mathrm{R}$ Foundation, Vienna, Austria).

\section{Handling of missing values and items}

Missing values were reported for each parameter throughout the analyses. For the Fatigue Scale for Motor and Cognitive Functions (FSMC $)^{20}$ and Beck Depression Inventory II (BDI-II) $)^{21}$ patient questionnaires, missing items were handled as follows: missing items were imputed using mean imputation, if 3 items, at most, were missing; if more than 3 items were missing, the whole questionnaire was classified as a missing value.

\section{Results}

\section{Clinical and demographic characteristics of the cohort}

After data monitoring, 1,124 baseline data sets were sufficient for analysis. Of 1,124 patients, $44.6 \%$ were diagnosed with CIS and 55.3\% with RRMS at inclusion (figure 1A). The sex distribution was a female-to-male ratio of 2.2:1 (figure 1B). Table 3 outlines the patient characteristics at baseline.

At baseline, the median EDSS $^{18}$ score was 1.5 (IQR: 1.0-2.0, table 3), with 23 patients (2.0\%) demonstrating an EDSS score of 4.0 or higher. The EDSS score ranged from 0 to 6.0, in total, within this visit. The initial presentation was monosymptomatic in $74.0 \%$ of the cohort. Figure $1 \mathrm{C}$ further characterizes these issues.

\section{Disease-modifying treatment}

A total of $67.8 \%$ of patients started DMT after a median time of 167.0 days (IQR: 90.0-377.5) after the first manifestation. In the treated population, 324 patients had CIS, while 438 had RRMS, resulting in a frequency of $64.7 \%$ and $70.4 \%$ of patients with CIS and RRMS, respectively, receiving DMT. Dissecting time intervals from the first manifestation to DMT initiation for diagnosis, the median interval for the CIS group was 107.0 days (IQR: 72.0-212.0), but 242.0 days (IQR: 120.0-466.0) for the RRMS group. By contrast, the median interval from diagnosis of RRMS to DMT initiation was 88.0 days (IQR: 52.0-167.0). Table 4 outlines the distribution of DMT, demonstrating a proportion of $80.2 \%$ with established injectables (interferon- $\beta$ or glatiramer acetate). This proportion was slightly higher in the CIS group (87.0\%). Nevertheless, a small proportion of patients were early treated with highly active agents, such as alemtuzumab, fingolimod, mitoxantrone, natalizumab, and even off-label rituximab, as their first-line therapy (table 4).

\section{Neuropsychological findings}

Table 5 shows the results of the neuropsychological assessments at baseline. Despite the overall low EDSS score in this cohort, approximately $36.5 \%$ of patients reported at 


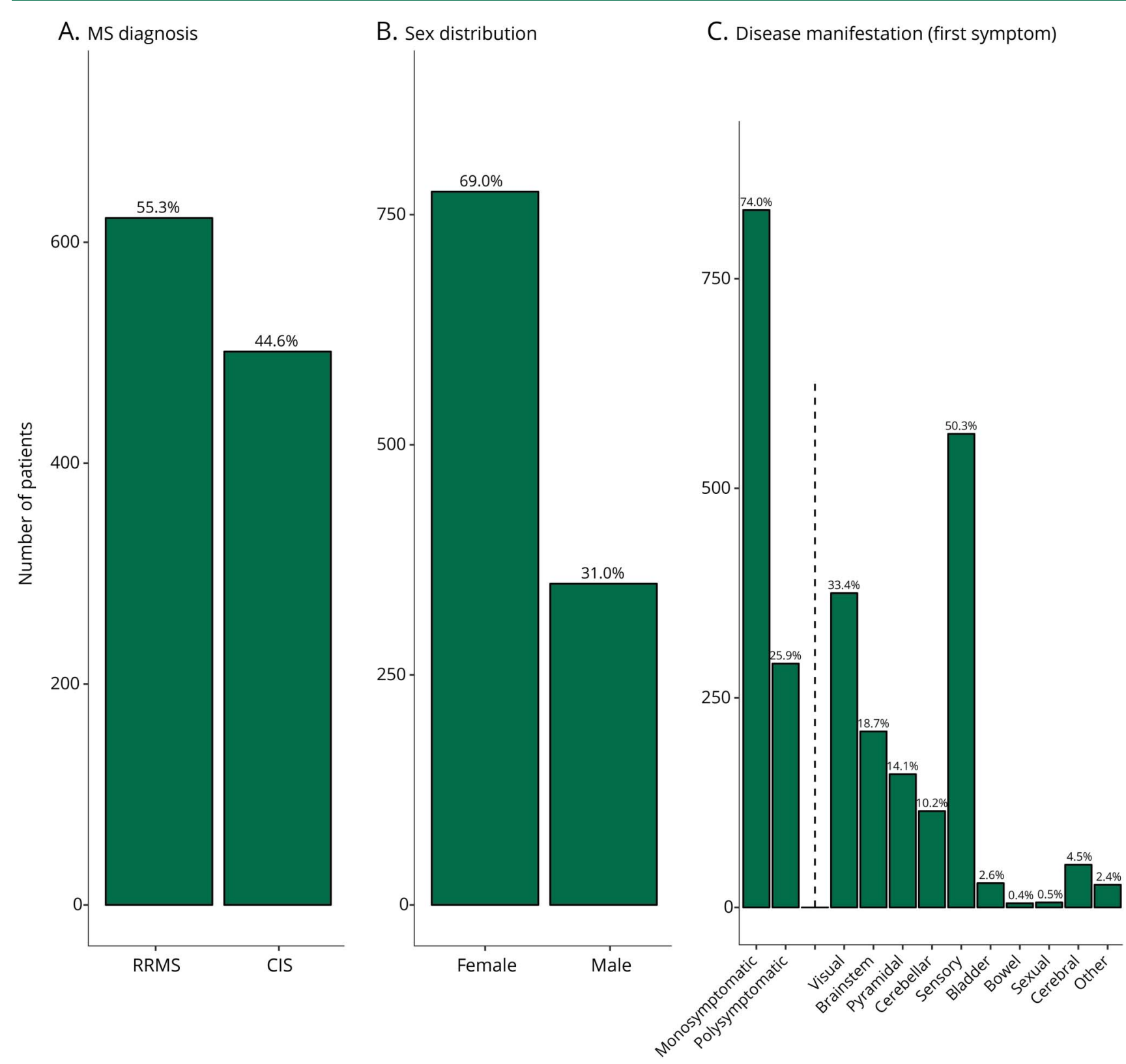

(A) Diagnosis at inclusion, $\mathrm{n}=1$ missing value, (B) sex distribution, and (C) first symptom at disease onset: monosymptomatic vs polysymptomatic and distribution according to EDSS functional systems. CIS = clinically isolated syndrome; EDSS = Expanded Disability Status Scale; RRMS = relapsing-remitting MS

least mild symptoms of fatigue. Almost a quarter of patients reported moderate fatigue, whereas $13.5 \%$ of patients reported severe fatigue at these early stages of the disease. Furthermore, approximately $33.5 \%$ of patients showed, "At least minimal depressive symptoms," which were defined by 9 or more points in BDI-II. A total of $14.7 \%$ of patients exhibited detectable neurocognitive deficits with the applied screening battery.

\section{Explorative correlation analyses}

Physical disability was measured using the EDSS, whereas neuropsychological findings were measured using the FSMC, BDI-II, and Multiple Sclerosis Inventory of Cognition
(MUSIC). ${ }^{22}$ Table 6 outlines the results of the explorative correlation analyses between physical disability and neuropsychological scales.

EDSS only showed weak correlations to fatigue, depression, and cognitive performance (table 6 and figure e-1, A-C, links. lww.com/NXI/A38). Cognitive performance, as measured with the MUSIC screening test, and depression were not correlated (table 6). Fatigue and depression were moderately correlated (Kendall's tau-b: 0.55 [0.52-0.58], table 6, figure e-2A, links.lww.com/NXI/A38). The positive correlation between the FSMC (total score) and BDI-II persisted even after the exclusion of overlapping questions from the 
Table 3 Baseline demographic data of the German National MS Cohort

\begin{tabular}{|c|c|}
\hline Age at inclusion (yrs) (median, IQR) & $32.40(26.55-40.98)$ \\
\hline Age at the first manifestation/CIS (yrs) (median, IQR) & $31.71(26.06-40.33)$ \\
\hline Disease duration at baseline-whole group (yrs) (median, IQR) ${ }^{a}$ & $0.33(0.20-0.70)$ \\
\hline Disease duration at baseline-only CIS (yrs) (median, IQR)a & $0.24(0.17-0.37)$ \\
\hline Disease duration at baseline-only RRMS (yrs) (median, IQR) ${ }^{a}$ & $0.51(0.25-1.15)$ \\
\hline Age at RRMS diagnosis-only RRMS (yrs) (median, IQR) & $31.67(26.50-40.33)$ \\
\hline Time from RRMS diagnosis at baseline-only RRMS (yrs) (median, IQR) & $0.17(0.11-0.31)$ \\
\hline EDSS at baseline, available for $n=1,121$ patients (median, IQR) & $1.5(1.0-2.0)$ \\
\hline BMI at baseline $\left(\mathrm{kg} / \mathrm{m}^{2}\right)$, available for $n=1,101$ patients (median, IQR) & $24.22(21.63-27.66)$ \\
\hline Smoking behavior ("ever-smoking"), available for $n=1,102$ patients ( $n, \%)$ & $366(33.2 \%)$ \\
\hline Alcohol consumption ("ever-consuming"), available for $n=1,105$ patients $(n, \%)$ & $812(73.5 \%)$ \\
\hline
\end{tabular}

BDI-II (Kendall's tau-b after exclusion: 0.46 [0.42-0.49], figure e-2B, links.lww.com/NXI/A38).

Finally, with the low EDSS score at this early stage of disease, it was poorly correlated with body mass index (BMI) (Kendall's tau-b: 0.12 [0.07-0.16], table 6).

\section{Discussion}

This comprehensive analysis describes patients in the early stages of MS in the largest German prospective MS cohort from 22 academic centers. The main finding of the current study was the frequent early occurrence of fatigue, depressive symptoms, and cognitive dysfunction, which was observed in $36.5 \%, 33.5 \%$, and $14.7 \%$ of patients, respectively. This underscores that MS greatly affects nonmotor symptoms and the quality of life, even at its early stages.

The median age of 31.71 years at disease onset is consistent with previous publications. ${ }^{23}$ However, given the inclusion criteria of this prospective study with the aim of a wellcontrolled uniform cohort for long-term follow-up, only

Table 4 First disease-modifying treatments (DMTs) in the German National MS Cohort

\begin{tabular}{llll}
\hline Disease-modifying treatment & All patients: frequency, $\mathbf{n}(\%)$ & CIS: frequency, $\mathbf{n}(\%)$ & RRMS: frequency, $\mathbf{n}(\%)$ \\
\hline Study medication (blinded) & $2(0.3)$ & $0(0.0)$ & $2(0.5)$ \\
\hline Alemtuzumab & $3(0.4)$ & $0(0.0)$ & $3(0.7)$ \\
\hline Azathioprine & $2(0.3)$ & $2(0.6)$ & $0(0.0)$ \\
\hline Dimethyl fumarate and other fumaric acid formulations & $79(10.4)$ & $23(7.1)$ & $56(12.8)$ \\
\hline Fingolimod & $22(2.9)$ & $5(1.5)$ & $17(3.9)$ \\
\hline Glatiramer acetate & $178(23.3)$ & $80(24.7)$ & $98(22.4)$ \\
\hline Interferon- $\beta$ formulations & $434(56.9)$ & $202(62.3)$ & $231(52.7)$ \\
\hline Mitoxantrone & $1(0.1)$ & $0(0.0)$ & $1(0.2)$ \\
\hline Natalizumab & $27(3.5)$ & $6(1.9)$ & $21(4.8)$ \\
\hline Rituximab & $1(0.1)$ & $0(0.0)$ & $1(0.2)$ \\
\hline Teriflunomide & $14(1.8)$ & $6(1.9)$ & $8(1.8)$ \\
\hline Total & 763 patients & 324 patients & 438 patients \\
\hline
\end{tabular}


Table 5 Results of neuropsychological assessments at baseline: Symptom frequencies by severity

\begin{tabular}{|c|c|c|}
\hline Test battery & Degree of severity & Frequency, $\mathrm{n}(\%)$ \\
\hline \multirow[t]{3}{*}{ FSMC-total score, available for $n=1,069$ patients } & At least mild fatigue (>42 Pt.) & $390(36.5)$ \\
\hline & At least moderate fatigue ( $>52 \mathrm{Pt}$.) & $261(24.4)$ \\
\hline & Severe fatigue (>62 Pt.) & $144(13.5)$ \\
\hline \multirow[t]{3}{*}{ FSMC-cognitive fatigue, available for $n=1,069$ patients } & At least mild fatigue (>21 Pt.) & $375(35.1)$ \\
\hline & At least moderate fatigue ( $>27 \mathrm{Pt}$.) & $226(21.1)$ \\
\hline & Severe fatigue (>33 Pt.) & $116(10.9)$ \\
\hline \multirow[t]{3}{*}{ FSMC-motor fatigue, available for $n=1,069$ patients } & At least mild fatigue (>21 Pt.) & $410(38.4)$ \\
\hline & At least moderate fatigue ( $>26 \mathrm{Pt}$.) & $273(25.5)$ \\
\hline & Severe fatigue (>31 Pt.) & $155(14.5)$ \\
\hline \multirow[t]{4}{*}{ BDI-II, available for $n=1,073$ patients } & At least minimal (>8 Pt.) & $359(33.5)$ \\
\hline & At least mild (>13 Pt.) & $185(17.2)$ \\
\hline & At least moderate (>19 Pt.) & $88(8.2)$ \\
\hline & Severe (>28 Pt.) & $27(2.5)$ \\
\hline \multirow[t]{3}{*}{ MUSIC, available for $n=1,064$ patients } & At least mild (<20 Pt.) & $157(14.7)$ \\
\hline & At least moderate (<16 Pt.) & $60(5.6)$ \\
\hline & Severe (<11 Pt.) & $8(0.8)$ \\
\hline
\end{tabular}

Abbreviations: BDI-II = Beck Depression Inventory II; FSMC = Fatigue Scale for Motor and Cognitive Functions; MUSIC = Multiple Sclerosis Inventory of Cognition; Pt. = points.

recently diagnosed adult patients were enrolled. Thus, the current study could not analyze the spectrum of childhoodonset MS or progressive forms of the disease. The female preponderance (2.2:1 female-to-male ratio) is in accord with published data. $4,11,23$

Table 6 Explorative correlation analyses

\begin{tabular}{ll}
\hline Variables & Kendall's tau (CI) \\
\hline FSMC total score vs EDSS & $0.24(0.20$ to 0.29$)$ \\
\hline FSMC motor fatigue vs EDSS & $0.25(0.21$ to 0.29$)$ \\
\hline FSMC cognitive fatigue vs EDSS & $0.22(0.17$ to 0.26$)$ \\
\hline FSMC total score vs BDI-II & $0.55(0.52$ to 0.58$)$ \\
\hline FSMC motor fatigue vs BDI-II & $0.53(0.50$ to 0.56$)$ \\
\hline FSMC cognitive fatigue vs BDI-II & $0.54(0.51$ to 0.57$)$ \\
\hline BDI-II vs EDSS & $0.20(0.16$ to 0.25$)$ \\
\hline MUSIC vs EDSS & $-0.13(-0.17$ to -0.08$)$ \\
\hline MUSIC vs BDI-II & $-0.10(-0.14$ to -0.06$)$ \\
\hline BMI vs EDSS & $0.12(0.07$ to 0.16$)$
\end{tabular}

Abbreviations: BDI-II = Beck Depression Inventory II; BMI = body mass index: EDSS = Expanded Disability Status Scale; FSMC = Fatigue Scale for Motor and Cognitive Functions; MUSIC = Multiple Sclerosis Inventory of Cognition.
Disease onset was mainly monosymptomatic, with sensory or visual symptoms being the most prevalent. This is in line with data demonstrating that visual and sensory symptoms typically occur early during the disease course and preferentially affect younger and female patients. ${ }^{24}$ This may also have implications for recovery from relapse. ${ }^{24}$

In the current cohort, EDSS revealed a generally low physical disability (median EDSS: 1.5) because of early inclusion of patients. Nevertheless, $2.0 \%$ of the cohort already exhibited severe impairment (EDSS: 24.0 ) at early disease stages. Because this analysis only depicts baseline data, we cannot exclude primarily relapse-driven disability at this time point that may not be confirmed during follow-up as sustained disability. Nevertheless, this might reflect disease heterogeneity with milder vs more severe initial symptoms and highly aggressive disease onset in a low percentage of patients.

BMI, especially adolescent obesity, which is an influencing factor of disease susceptibility, could affect disease severity and progression. ${ }^{25,26}$ Although the median BMI in the current cohort was $24.22 \mathrm{~kg} / \mathrm{m}^{2}$ (IQR: 21.63-27.66), $15.1 \%$ of patients had a BMI of $30 \mathrm{~kg} / \mathrm{m}^{2}$ or higher. There was only a poor correlation between BMI and physical disability (i.e., the EDSS), which might change with further observation of the cohort. Smoking (ever smoking 33.2\%) showed a comparable prevalence in the general German population. ${ }^{27}$ 
It influences the acceleration of disease course with 1.34 and 1.25 times higher odds of reaching EDSS scores of 4.0 and 6.0, respectively. ${ }^{28}$

More than two-thirds of patients in our cohort received DMT, which was comparable with the MSBase data set. ${ }^{4}$ Because recruitment mostly occurred via academic centers, however, this might produce a selection bias, and thus, the data might not be representative of the general German population. Moreover, progressive forms of disease were not included. The patients in the current cohort started treatment only recently, and thus, it would be premature to draw conclusions on adherence. Given the broad access to medical supply in the German health care system, the frequency of DMT for patients with CIS (64.7\%) and RRMS (70.4\%) was quite similar to the current cohort. Yet, the interval from the first manifestation to DMT initiation differed; the median interval was 107.0 days (IQR: 72.0-212.0) for patients with CIS, whereas it was 242.0 days (IQR: 120.0-466.0) for those with RRMS. By contrast, the interval from diagnosis of RRMS to DMT initiation was markedly shorter (88.0 days [IQR: 52.0-167.0]). A possible explanation for this finding is that patients were enrolled in centers that were experienced with MS diagnosis and treatment. Therefore, it is more likely that patients who were diagnosed with CIS and RRMS in the center were counseled to initiate DMT early. For RRMS, it is possible that the first manifestation did not even lead to a medical consultation or consultation in a nonspecialized setting, which might affect the timing of treatment initiation. All our reported intervals were still much shorter than in a large previous analysis, which started 15 years earlier than this cohort. ${ }^{3}$ This might partly be explained by changes in diagnostic criteria over time because parts of our CIS cohort will putatively already fulfill McDonald criteria $2010^{29}$ for RRMS. Again, we cannot exclude a center bias. A further general change in MS treatment paradigms toward an earlier treatment initiation in the last decade has to be discussed as well. The overall treatment distribution comprised $80.2 \%$ of treated patients with interferon- $\beta$ formulations or glatiramer acetate. Yet, in line with the notion that patients with aggressive disease onset and high EDSS at baseline were enrolled, there were patients receiving highly active DMT as the first treatment. It must be noted that patients diagnosed with CIS but treated with oral DMTs by the independent neurologist may already fulfill diagnostic criteria according to the McDonald 2010 revisions. ${ }^{29}$ Lower frequencies of more active DMT might reflect a prevailing DMT paradigm of escalation rather than induction in most patients. It must also be noted that DMTs such as alemtuzumab, for instance, which may qualify for induction strategies, were only available at the end of the recruitment period.

Neuropsychological symptoms in this early MS cohort affected a relevant proportion of patients: At baseline, 36.5\% and $24.4 \%$ of patients reported at least mild and moderate fatigue symptoms, respectively, despite the low physical disability measured by EDSS. However, the prevalence rates of fatigue in MS are still hardly comparable between published cohorts, given the considerable variation in assessment instruments. ${ }^{8-10}$ The FSMC is currently possibly the most suitable tool to assess fatigue in $\mathrm{MS} .^{20}$ Because our cohort is an early, well-defined cohort with regular follow-up, the evolution of fatigue can be thoroughly assessed over time. Similarly, we can also study its longitudinal relationship with depression and cognitive function. The pathophysiology of fatigue in MS may include both autoimmune inflammatory processes associated with myelin and axonal damage and factors such as sleep disturbance, vigilance regulation, depression, inactivity, disability status, and side effects of medication. ${ }^{10,30}$ Our study may help to further elucidate these factors as MRI and laboratory dates become available. The interaction of fatigue and depression, which, like in other studies, correlated, even after controlling for fatigue contaminated items of the BDI must at this stage be cautiously interpreted as we did not yet control for confounding factors. One might argue about the clinical relevance of minimal symptoms of depression that were present in $33.4 \%$ of patients. This percentage might partly reflect the early adjustment processes to the diagnosis. However, depression rates might indicate a response to chronic illness or even a specific trait related to MS immunopathology. ${ }^{12}$ Psychological interventions should be available for the relevant proportion of $17.2 \%$ of patients with mild or more severe depression.

The large data set of our cohort demonstrated that $14.7 \%$ of the patients displayed cognitive dysfunction detectable with a screening instrument. Because MUSIC has only been validated in German, comparative data to other neuropsychological batteries are missing thus far. This represents a major limitation to the study. However, it covers major cognitive impairment domains in MS in a 20-minute examination. As expected, the prevalence of cognitive decline in unselected MS populations is higher. ${ }^{14}$ There is a current scientific discussion on whether cognitive symptoms appear before the first clinical MS symptoms as an indicator of diffuse brain damage. ${ }^{31}$ However, the prevalence and evolution of cognitive dysfunction, as well as the influence of DMT on this domain in MS, are still poorly understood. Thus, further longitudinal data sets are warranted. Early focused neurocognitive assessment is crucial to recognize early cognitive symptoms, especially in terms of long-term treatment evaluations to assess possible effects on clinically relevant cognitive functioning over time.

In contrast to previous data, ${ }^{32}$ the applied battery of tests did not reveal an association between depression and cognition in the current study. This might be due to the mild severity of both or be attributed to a short disease duration with preserved cognition leading to patients with depression still performing well in cognitive screening. Yet, this needs to be cautiously discussed because these first analyses were not controlled for confounders at this stage and the MUSIC battery has not been evaluated in this context before. 
Furthermore, similar to fatigue and depression, MUSIC results poorly correlated with EDSS, with respect to the caveats mentioned above. This corroborated with previous investigations $^{22}$ and underlines the weakness of the EDSS in detecting these domains. This also highlights the need for distinct assessments in the early stages of MS.

Baseline data of this large multicenter cohort provide an important insight into early MS. Relevant demographic data were prospectively confirmed for a German population for the first time, and the distribution of DMTs was elucidated. Neuropsychological comorbidities, which can be detected with screening batteries, seem relevant in the earliest stages of MS. Because they affect a large proportion of patients, but are not reflected by EDSS, distinct routine clinical assessment of these neuropsychological comorbidities is an unmet need in patient care. This may also have therapeutic implications. Although, thus far, neuropsychiatric interventions in MS are not highly developed, increased awareness and assessment sensitivity for a clinically relevant symptomatology could further help treatment development.

\section{Author contributions}

O. von Bismarck: analysis of data and drafting the manuscript. T. Dankowski: analysis and interpretation of data and drafting the manuscript. B. Ambrosius: drafting the manuscript. N. Hessler: analysis and interpretation of data and revising the manuscript. G. Antony: design and conceptualization of the study. A. Ziegler, M.-M. Hoshi, L. Aly, F. Luessi, S. Groppa, L. Klotz, S.G. Meuth, B. Tackenberg, M. Stoppe, F.T. Bergh, H. Tumani, T. Kümpfel, M. Stangel, C. Heesen, B. Wildemann, F. Paul, A. Bayas, C. Warnke, F. Weber, R.A. Linker, U. Ziemann, and U.K. Zettl: revising the manuscript. F. Zipp, H. Wiendl, B. Hemmer, and R. Gold: design and conceptualization of the study and revising the manuscript. A. Salmen: design and conceptualization of the study, analysis and interpretation of data, and drafting the manuscript.

\section{Acknowledgment}

The authors and representatives of the KKNMS express their deep gratitude to all contributors of the study, especially the study nurses, for their motivated collaboration and recruitment efforts, all the patients and relatives for their participation and support, and the data monitoring and administrative personnel of the study.

\section{Study funding}

The German National MS Cohort and KKNMS are supported by grants from the German Federal Ministry for Education and Research (BMBF), grant no. 01GI0914 (Bochum), 01GI0916, 01GI1601G (Lübeck), and 01GI1601B (Marburg).

\section{Disclosure}

O. von Bismark and T. Danowski report no disclosures. B. Ambrousis received travel funding from Novartis and research support from FORUM Anschubfinanzierung, Medizinische
Fakultät Ruhr-Universität Bochum, Förderkennzeichen. N. Hessler reports no disclosures. G. Antony received research support from the German Ministry of Education and Research, EU, University Marburg. A. Ziegler received research support from the German Ministry of Education and Research. M.-M. Hoshi served on the scientific advisory board of Merck Serono and received travel funding from Bayer. L. Aly, F. Luessi, and S. Groppa report no disclosures. L. Klotz served on the scientific advisory board of Genzyme, Novartis, and Biogen; received speaker honoraria and travel funding from Novartis, Merck Serono, and CSL Behring; and received research support from Novartis, Biogen, CRC, the Federal Ministry of Education and Research, and Competence Network Multiple Sclerosis. S.G. Meuth served on the scientific advisory board of Almirall, Bayer, Biogen, Genzyme, Merck Serono, Novartis, Novo Nordisk, Roche, Sanofi-Aventis, Teva, Diamed, MedDay, and Ono Pharma; received travel funding and/or speaker honoraria from Almirall, Bayer, Biogen, Genzyme, Merck Serono, Novartis, Novo Nordisk, Roche, Sanofi-Aventis, Teva, Diamed, MedDay, and Ono Pharma; served on the editorial board of PLoS One; holds patents for Effectivity of specific FCII/FCIIa inhibitors, particularly rHA-Infestin 4 used to treat neuro-inflammatoral disease, diagnosis of a novel autoimmune disease; and consulted for and received research support from Almirall, Bayer, Biogen, Genzyme, Merck Serono, Novartis, Novo Nordisk, Roche, Sanofi-Aventis, Teva, Diamed, MedDay, and Ono Pharma. B. Tackenberg served on the scientific advisory board of and received consulting fees from Biogen, Bayer, Novartis, Merck Serono, Octapharma, CSL Behring, and Grifols; received speaker honoraria from Biogen, Bayer, Novartis, Merck Serono, Teva, Sanofi-Aventis, Octapharma, CSL Behring, Grifols, and GSK; and received research support from Bayer, Biogen, Novartis, Sanofi-Aventis, the Marburg University Trust, Förderverein Neurologie, e.g., German Myasthenia Gravis Society and German Society of Neurology. M. Stoppe reports no disclosures. F.T. Bergh received speaker honoraria and consulting fees as a speaker and advisory member from Bayer, Biogen, Merck Serono, Novartis, Roche, Sanofi Genzyme, and Teva and received research support from Actelion, Novartis, Teva, and the German Federal Ministry of Research. H. Tumani reports no disclosures. 1 T. Kumpfel received travel funding and/or speaker honoraria from Bayer, Teva, Merck, Novartis, Sanofi-Aventis/Genzyme, CSL Behring, Roche, and Biogen and received grant support from Bayer Schering Pharma AG, Novartis, and Chugai Pharmaceutical. M. Stangel served on the scientific advisory board of Biogen, Baxalta/Shire, CSL Behring, Grifols, MedDay, Merck Serono, Novartis, Roche, Sanofi Genzyme, and Teva; received travel funding and speaker honoraria from Bayer HealthCare, Biogen, CSL Behring, Merck Serono, Novartis, Roche, Sanofi Genzyme, and Teva; is an academic editor for PLoS One and is on the editorial board of Multiple Sclerosis International; and received research support from Biogen, Merck Serono, Novartis, Sanofi Genzyme, Teva, Deutsche Forschungsgemeinschaft, Bundesministerium für Bildung, und Forschung. C. Heesen received speaker honoraria from 
Biogen, Merck Genzyme, and Novartis; is on the editorial board of the International Journal of MS Care; and received research support from Genzyme, Biogen, Roche, Novartis, Merck, Sanofi-Aventis, and the German Ministry of Research. B. Wildemann served on the scientific advisory board of Novartis, Sanofi Genzyme, and Roche; received travel funding and/or speaker honoraria from Biogen, Merck Serono, Novartis, Teva, and Sanofi Genzyme; and received research support from Bundesministerium für Forschung and Technologie, Dietmar Hopp Stiftung, Klaus Tschira Stiftung, Merck Serono, Novartis, and Sanofi Genzyme. F. Paul is on the study steering committee of Novartis OCTIMS study; received speaker honoraria and travel funding from Bayer, Novartis, Biogen, Teva, Sanofi-Aventis/Genzyme, Merck Serono, Alexion, Chugai Pharmaceutical, MedImmune, and Shire; is an associate editor of Neurology ${ }^{\circledR}$ Neuroimmunology o Neuroinflammation and an academic editor of PLoS One; consulted for Sanofi Genzyme, Biogen, MedImmune, Shire, and Alexion; and received research support from Bayer, Novartis, Biogen, Teva, Sanofi-Aventis/Genzyme, Alexion, Merck Serono, the German Research Council, Werth Stiftung of the City of Cologne, the German Ministry of Education and Research, Arthur Arnstein Stiftung Berlin, EU FP7 Framework Program, the Guthy Jackson Charitable Foundation, the Arthur Arnstein Foundation, and the National Multiple Sclerosis Society. A. Bayas served on the scientific advisory board of Merck Serono, Biogen, Novartis, Teva, Sanofi/ Genzyme, and Roche; received travel funding and speaker honoraria from Merck Serono, Biogen, Novartis, Teva, and Sanofi/Genzyme; and consulted for Merck Serono, Biogen, and Novartis. C. Warnke received speaker honoraria from Novartis, Biogen, Bayer, and Teva; is an associate editor of Frontiers in Neurology; and received research support from the Hertie Foundation and the Charcot Foundation. F. Weber served on the scientific advisory board of Genzyme and Novartis; received travel funding and/or speaker honoraria from Biogen, Teva, Merck Serono, Novartis, and Pfizer; is employed by Sana; and received research support from Merck Serono, Novartis, and MBMF. R.A. Linker served on the scientific advisory board of Biogen Genzyme, Merck, Novartis, Roche, and Teva; received travel funding and/or speaker honoraria from Biogen, Genzyme, Merck, Novartis, Roche, and Teva; and consulted for Biogen, Novartis, and Roche. U. Ziemann served on the scientific advisory board of CorTec $\mathrm{GmbH}$; received speaker honoraria from Bayer, Biogen, Bristol Myers Sqibb, Medtronic, and Pfizer; was editor-in-chief of Clinical Neurophysiology, was associate editor of the Journal of Neuroscience, was deputy editor of Brain Stimulation, and was an editorial advisory member of Experimental Brain Research; received publishing royalties from Elsevier, Springer, and Oxford University Press; and received research support from Biogen, Janssen, and Servier. U.K. Zettl received speaker honoraria and travel funding from Bayer, Aventis, Teva, Merck-Serono, and Biogen. F. Zipp served on the scientific advisory board of and received travel funding and/or speaker honoraria from Teva, Merck Serono, Novartis, Bayer HealthCare, Biogen, Ono Pharma, Genzyme,
Sanofi-Aventis, and Octapharma and received research support from Teva, Merck Serono, Novartis, Bayer, DFG CRC-TRR, DFG CRC1080, BMBF KKNMS, Progressive MS Alliance, and PRAG-MS. H. Wiendl served on the scientific advisory board of Bayer, Biogen, Sanofi Genzyme, Merck Serono, Novartis, Roche, and Teva; received travel funding and/or speaher honoraria from Bayer Vital, Bayer Schering, Biogen, CSL Behring, EMD Serono, Fresenius Medical Care, Sanofi Genzyme, Merck Serono, Omniamed, Novartis, Teva, GlaxoSmithKline, and GQ Pharmaceuticals; is on the editorial board of PLoS One, Neurotherapeutics, and Recent Patents on Inflammation \& Allergy Drug Discovery; consulted for Biogen, Merck Serono, Novartis, Omniamed, Roche, and Sanofi Genzyme; and received research support from Bayer, Bayer Vital, Biogen, Merck Serono, Novartis, Sanofi Genzyme, Sanofi US, Teva, the German Ministry for Education and Research, Interdisciplinary Centre of Clinical Research, the PML Consortium, the German Research Foundation, the Else Kroner Fresenius Foundation, the Fresenius Foundation, the Hertie Foundation, and the RE Children's Foundation. B. Hemmer served on the scientific advisory board of F. Hoffmann-la Roche, Novartis, Bayer, and Genentech; served as a DMSC member of AllergyCare; received speaker honoraria (paid to him or his institution) from Biogen, Teva, Merck Serono, MedImmune, Novartis, Desitin, Hoffman-La Roche, and EXCEMED; served on the editorial board of JAMA Neurology and MS Journal; holds patents for Detection of antibodies and T-cells against KIR4 in a subpopulation of MS patients, genetic determinants of neutralizing antibodies to interferon B; and received research support from Chugai Pharmaceuticals, the German Research Foundation, the German Ministry of Education and Research, EU Horizon, and EU IMI. R. Gold served on the scientific advisory board of Teva Laquinimod DSMB; received speaker honoraria from Biogen, Genzyme, Teva, Merck Serono, BayerSchering, Ozgene, and Novartis; and is on the editorial board of SAGE Journal, Aktuelle Neurologie, and Experimental Neurology. A. Salmen received speaker honoraria and/or travel funding from Almirall, Hermal GmbH, Biogen, Merck, Novartis, Roche, and Sanofi Genzyme. Full disclosure form information provided by the authors is available with the full text of this article at Neurology.org/NN.

Received November 5, 2017. Accepted in final form January 12, 2018.

\section{References}

1. Petersen G, Wittmann R, Arndt V, Gopffarth D. Epidemiology of multiple sclerosis in Germany: regional differences and drug prescription in the claims data of the statutory health insurance [in German]. Nervenarzt 2014;85:990-998.

2. Kalincik T, Butzkueven H. Observational data: understanding the real MS world. Mult Scler 2016;22:1642-1648.

3. Tintore M, Rovira A, Rio J, et al. Defining high, medium and low impact prognostic factors for developing multiple sclerosis. Brain 2015;138:1863-1874.

4. Kalincik T, Kuhle J, Pucci E, et al. Data quality evaluation for observational multiple sclerosis registries. Mult Scler 2017;23:647-655.

5. Marrie RA, Cohen J, Stuve O, et al. A systematic review of the incidence and prevalence of comorbidity in multiple sclerosis: overview. Mult Scler 2015;21:263-281.

6. van't Leven M, Zielhuis GA, van der Meer JW, Verbeek AL, Bleijenberg G. Fatigue and chronic fatigue syndrome-like complaints in the general population. Eur J Public Health 2010;20:251-257.

7. Martin A, Chalder T, Rief W, Braehler E. The relationship between chronic fatigue and somatization syndrome: a general population survey. J Psychosomatic Res 2007; 63:147-156. 
8. Fox RJ, Bacon TE, Chamot E, et al. Prevalence of multiple sclerosis symptoms across lifespan: data from the NARCOMS Registry. Neurodegener Dis Manag 2015;5:3-10.

9. Greeke EE, Chua AS, Healy BC, Rintell DJ, Chitnis T, Glanz BI. Depression and fatigue in patients with multiple sclerosis. J Neurol Sci 2017;380:236-241.

10. Weiland TJ, Jelinek GA, Marck CH, et al. Clinically significant fatigue: prevalence and associated factors in an international sample of adults with multiple sclerosis recruited via the internet. PLoS One 2015;10:e0115541.

11. Stuke K, Flachenecker P, Zettl UK, et al. Symptomatology of MS: results from the German MS registry. J Neurol 2009;256:1932-1935.

12. Marrie RA, Reingold S, Cohen J, et al. The incidence and prevalence of psychiatric disorders in multiple sclerosis: a systematic review. Mult Scler 2015;21:305-317.

13. Maske UE, Buttery AK, Beesdo-Baum K, Riedel-Heller S, Hapke U, Busch MA Prevalence and correlates of DSM-IV-TR major depressive disorder, self-reported diagnosed depression and current depressive symptoms among adults in Germany. J Affect Disord 2016;190:167-177.

14. Chiaravalloti ND, DeLuca J. Cognitive impairment in multiple sclerosis. Lancet Neurol 2008;7:1139-1151.

15. Sachdev PS, Lipnicki DM, Kochan NA, et al. The prevalence of mild cognitive impairment in diverse geographical and ethnocultural regions: the COSMIC collaboration. PLoS One 2015;10:e0142388.

16. Amato MP, Ponziani G, Rossi F, Liedl CL, Stefanile C, Rossi L. Quality of life in multiple sclerosis: the impact of depression, fatigue and disability. Mult Scler 2001;7: 340-344.

17. Goksel Karatepe A, Kaya T, Gunaydn R, Demirhan A, Ce P, Gedizlioglu M. Quality of life in patients with multiple sclerosis: the impact of depression, fatigue, and disability. Int J Rehabil Res 2011;34:290-298.

18. Kurtzke JF. Rating neurologic impairment in multiple sclerosis: an expanded disability status scale (EDSS). Neurology 1983;33:1444-1452.

19. Cutter GR, Baier ML, Rudick RA, et al. Development of a multiple sclerosis functional composite as a clinical trial outcome measure. Brain 1999;122:871-882.

20. Penner I, Raselli C, Stöcklin M, Opwis K, Kappos L, Calabrese P. The fatigue scale for motor and cognitive functions (FSMC): validation of a new instrument to assess multiple sclerosis-related fatigue. Mult Scler 2009;15:1509-1517.

21. Kühner C, Bürger C, Keller F, Hautzinger M. Reliability and validity of the revised Beck depression inventory (BDI-II). Results from German samples [in German]. Nervenarzt 2007;78:651-656.
22. Calabrese P, Kalbe E, Kessler J. Ein neuropsychologisches Screening zur Erfassung kognitiver Störungen bei MS-Patienten-Das Multiple Sklerose Inventarium Cognition (MUSIC). Psychoneuro 2004;30:384-388.

23. Manouchehrinia A, Beiki O, Hillert J. Clinical course of multiple sclerosis: a nationwide cohort study. Mult Scler 2017;23:1488-1495.

24. Kalincik T, Buzzard K, Jokubaitis V, et al. Risk of relapse phenotype recurrence in multiple sclerosis. Mult Scler 2014;20:1511-1522.

25. Bove R, Musallam A, Xia Z, et al. Longitudinal BMI trajectories in multiple sclerosis: sex differences in association with disease severity. Mult Scler Relat Disord 2016;8:136-140.

26. Hedstrom AK, Olsson T, Alfredsson L. Body mass index during adolescence, rather than childhood, is critical in determining MS risk. Mult Scler 2016;22:878-883.

27. Lampert T, von der Lippe E, Müters S. Prevalence of smoking in the adult population of Germany: results of the German Health Interview and Examination Survey for Adults (DEGS1). Bundesgesundheitsblatt Gesundheitsforschung Gesundheitsschutz 2013;56:802-808.

28. Manouchehrinia A, Tench CR, Maxted J, Bibani RH, Britton J, Constantinescu CS. Tobacco smoking and disability progression in multiple sclerosis: United Kingdom cohort study. Brain 2013;136:2298-2304.

29. Polman CH, Reingold SC, Banwell B, et al. Diagnostic criteria for multiple sclerosis: 2010 revisions to the McDonald criteria. Ann Neurol 2011;69:292-302.

30. Taylor KL, Hadgkiss EJ, Jelinek GA, et al. Lifestyle factors, demographics and medications associated with depression risk in an international sample of people with multiple sclerosis. BMC Psychiatry 2014;14:327.

31. Cortese M, Riise T, Bjornevik K, et al. Preclinical disease activity in multiple sclerosis: a prospective study of cognitive performance prior to first symptom. Ann Neurol 2016;80:616-624.

32. Portaccio E. Differential diagnosis, discerning depression from cognition. Acta Neurol Scand 2016;134(suppl 200):14-18.

33. Barkhof F, Filippi M, Miller DH, et al. Comparison of MRI criteria at first presentation to predict conversion to clinically definite multiple sclerosis. Brain 1997;120: 2059-2069.

34. Polman $\mathrm{CH}$, Reingold SC, Edan G, et al. Diagnostic criteria for multiple sclerosis: 2005 revisions to the "McDonald Criteria". Ann Neurol 2005;58:840-846.

35. Freynhagen R, Baron R, Gockel U, Tolle TR. painDETECT: a new screening questionnaire to identify neuropathic components in patients with back pain. Curr Med Res Opin 2006;22:1911-1920. 


\section{Neurology \\ Neuroimmunology \& Neuroinflammation}

\section{Treatment choices and neuropsychological symptoms of a large cohort of early MS \\ Olga von Bismarck, Theresa Dankowski, Björn Ambrosius, et al. \\ Neurol Neuroimmunol Neuroinflamm 2018;5; \\ DOI 10.1212/NXI.0000000000000446}

This information is current as of March 1, 2018

\section{Updated Information \& \\ Services}

References

Citations

Subspecialty Collections

Permissions \& Licensing

Reprints including high resolution figures, can be found at:

http://nn.neurology.org/content/5/3/e446.full.html

This article cites 35 articles, 0 of which you can access for free at: http://nn.neurology.org/content/5/3/e446.full.html\#\#ref-list-1

This article has been cited by 6 HighWire-hosted articles: http://nn.neurology.org/content/5/3/e446.full.html\#\#otherarticles

This article, along with others on similar topics, appears in the following collection(s):

Multiple sclerosis

http://nn.neurology.org//cgi/collection/multiple_sclerosis

Information about reproducing this article in parts (figures,tables) or in its entirety can be found online at:

http://nn.neurology.org/misc/about.xhtml\#permissions

Information about ordering reprints can be found online: http://nn.neurology.org/misc/addir.xhtml\#reprintsus

Neurol Neuroimmunol Neuroinflamm is an official journal of the American Academy of Neurology.

Published since April 2014, it is an open-access, online-only, continuous publication journal. Copyright

Copyright $\odot 2018$ The Author(s). Published by Wolters Kluwer Health, Inc. on behalf of the American

Academy of Neurology.. All rights reserved. Online ISSN: 2332-7812.

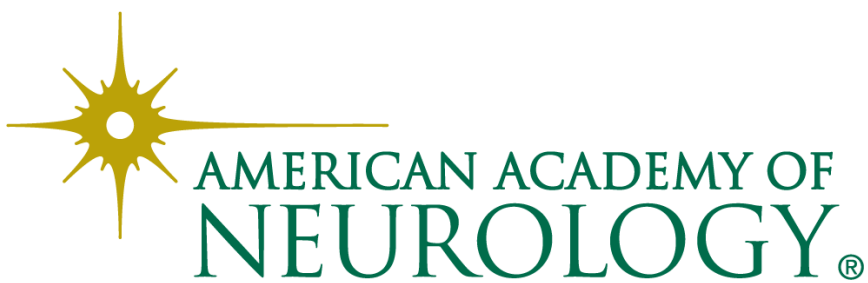

